Aim of the study: Oral mucositis is a common side effect of the oral mucosa due to anticancer therapy, especially for head and neck cancer. Caphosol is indicated for dryness of the mouth and oropharynx and treatment of mucositis due to irradiation or highdose chemotherapy. The aim of the study was to evaluate the efficacy of Caphosol in preventing and alleviating mucositis due to radiotherapy in the head and neck region.

Material and methods: Caphosol was used from the beginning of the irradiation and for two weeks more after the treatment was completed. Mucositis, xerostomia, and dysphagia were scored by radiotherapists. Subjective evaluation was made by patients. Caphosol was assessed in a non-blinded, matched clinical study. Each treatment arm consisted of $50 \mathrm{pa}$ tients. The groups were similar. The only difference in the management protocol between the treatment arms was the use of Caphosol in the experimental arm.

Results: A statistically significant difference in mean severity of early irradiation-induced side effects between the studied groups was observed with respect to: mucositis in the clinical target volume (CTV) area, mucositis in the increased dose (boost) area, dysphagia and xerostomia $(p<0.001$ for all reactions). In the group of patients who used Caphosol, the mucositis was less intense, both in the CTV and in the boost area.

Conclusions: The use of Caphosol reduces the severity of acute mucositis, dysphagia and xerostomia, exerting a positive effect on comfort in the oral cavity in patients irradiated for head and neck tumors.

Key words: head and neck, radiotherapy, mucositis, Caphosol.

Contemp Oncol (Pozn) 2016; 20 (5): 389-393 DOI: $10.5114 /$ wo.2016.64600

\section{Evaluation of efficacy of Caphosol in prevention and alleviation of acute side effects in patients treated with radiotherapy for head and neck cancers}

Dorota Kiprian, Andrzej Jarzabski, Andrzej Kawecki

Comprehencive Cancer Center, Warsaw, Poland

\section{Introduction}

Oral mucositis is a common side effect of the oral mucosa due to anticancer therapy, especially for head and neck cancer [1]. Chemotherapy is administered systemically, whereas radiation therapy affects a mucosal membrane locally. Post-irradiation mucositis typically manifests as erythema, swelling, atrophy and ulceration [2, 3]. Chemotherapy-induced mucositis usually develops within 4-7 days after initiation of treatment and lasts about 2 weeks. Radiation-induced mucositis typically begins at cumulative doses of about 10-15 Gy (about 10 days of treatment) and typically lasts for weeks after the treatment is completed. Severity of mucositis depends on many factors, related to therapy and patient characteristics such as the method of fractionation, the total dose, the treatment strategy, oral hygiene during the therapy, as well as individual genetic predispositions. The majority of patients treated for head and neck cancers or those receiving high-dose chemotherapy develop severe oral mucositis. Patients often complain of taste changes, difficulty in talking and swallowing, pain and oral dryness. Severe oral mucositis can lead to bacterial and fungal infection, difficulty with swallowing and decreased patient's quality of life. Significant progress has been made in understanding the pathobiology of mucositis in the last decade. The biological model of mucositis due to anticancer therapy proposed by Sonis in 2004 presents that mechanism as a cascade of pro-inflammatory cytokines TNF- $\alpha$, IL-1, and IL- 6 activated by free radicals. This pathobiological cascade is described in five phases: initiation, up-regulation with generation of messengers, signaling and amplification, ulceration with inflammation, and, finally healing [2]. The understanding of this molecular mechanism of radiation-induced mucositis has opened new possibilities for investigators to develop a proper strategy in prevention and treatment of mucositis. Management of oral mucositis has been the subject of many publication each year [4-6]. There are several products available for the prevention and treatment oral mucositis [7-9], but there are no gold standard strategies to prevent and treat oral mucositis. Based on a comprehensive systematic review of the literature, the Mucositis Study Group of the Multinational Association for Supportive Care in Cancer and the International Society of Oral Oncology (MASCC/ISOO) has developed clinical practice guidelines for the management of mucositis. The last guidelines were published in January and February 2013 in Supportive Care in Cancer [10-13]. That is why many new products and medicines are being investigated to tackle the problem of oral mucositis. Caphosol is a supersaturated solution of calcium phosphate. It is designed to moisten, lubricate and cleanse the mucosa, and replace key minerals (calcium and phosphate) which are involved in repairing and 
maintaining mucosal integrity. Calcium ions have an antiinflammatory function, lower the prostaglandin production and promote tissue regeneration. Phosphate ions can protect against infections and maintain an appropriate $\mathrm{pH}$ level. High concentrations of calcium and phosphate allow the ions to diffuse into intercellular epithelial spaces and permeate mucosal lesions.

\section{Aim of the study}

The aim of the study was to assess the efficacy of Caphosol in prevention and alleviation of acute side effects of irradiation in patients irradiated for head and neck cancer.

\section{Material and methods}

This study was performed in accordance with the global standards of the International Conference on Harmonization - Good Clinical Practices (ICH-GCP), the Council for International Organizations of Medical Sciences International Ethical Guidelines for Biomedical Research Involving Human Subjects (CIOMS, 2002), applicable local regulatory requirements and the ethical principles that have their origin in the Declaration of Helsinki. The study complies with all laws and

Table 1. Clinical material

\begin{tabular}{lccc} 
Therapy & \multicolumn{3}{c}{$\begin{array}{c}\text { Method } \\
\text { Number of patients }\end{array}$} \\
\cline { 2 - 4 } & 3 D & IMRT & SIB-IMRT \\
Radiotherapy alone & 1 & 14 & 5 \\
$\begin{array}{l}\text { Concomitant } \\
\text { radiochemiotherapy }\end{array}$ & 1 & 11 & 18 \\
\hline
\end{tabular}

Table 2. Clinical material

$\begin{array}{lc}\text { Diagnosis } & \begin{array}{c}\text { Number of patients } \\ (\mathrm{F}-\mathbf{1 5} \text {; }-\mathbf{3 5})\end{array} \\ \text { Nasopharyngeal cancer } & 13 \\ \text { Oropharyngeal cancer } & 18 \\ \text { Laryngeal and hypophlaryngeal cancer } & 5 \\ \text { Post-operative floor of the mouth cancer } & 8 \\ \text { Tongue cancer } & 4 \\ \text { Sarcoma of the mandibule post-operative } & 1 \\ \text { FPI } & 1\end{array}$

regulations in Poland and has been carried out in a manner respectful of the local culture and consistent with legal statutes and regulations for the protection of human subjects. Patients with head and neck cancer referred for radiotherapy or radiochemotherapy with radical intent were included in this study. Caphosol was assessed in a non-blinded, matched clinical study. Caphosol was used as a mouthwash from the first day of irradiation throughout the whole course of the therapy and two weeks after the treatment was completed. Initially, the patients used it for the oral cavity and the throat 4 times a day. The frequency of application was increased up to 10 times a day depending on the severity of symptoms associated with mucositis. The severity of acute side effects such as mucositis, dysphagia and xerostomia was assessed by a radiation oncologist according to the European Organization for Research and Treatment of Cancer/Radiation Therapy Oncology Group (EORTC/RTOG) scale once a week during the therapy and one month after its completion. Other criteria taken into consideration were: dietary supplements, the use of non-steroid anti-inflammatory drugs (NSAIDs), opioids, mucolytic agents, and prolonged hospitalization. The subjective assessment of patient satisfaction was made by completing a questionnaire.

\section{Material and statistical analysis}

The total number of patients included in this study was 100. The patients were matched into two arms equal in diagnosis and treatment strategy (Tables 1 and 2). In the experimental arm patients received Caphosol and in the control arm standard treatment, which was recommended in the Head and Neck Cancer Department.

Severity of the selected acute side effects (measured according to the RTOG/EORTC scale) according to a developed algorithm was adopted as a criterion of assessment. The mean value based on all measurements was analyzed as a continuous variable. Other criteria such as dietary supplements, use of non-steroid anti-inflammatory drugs (NSAIDs) and opioids as well as the fact of prolonged hospitalization were analyzed as a percentage of answers. Standard descriptive statistics tools - frequency tables and contingency tables for bivariate data, as well as maximum and minimum values, mean value and standard deviation for continuous variables with normal distribution, or quartiles in the case of different distribution - were used for description of the material. Student's

Table 3. Comparison of the severity of early reactions to irradiation in the analyzed groups.

\begin{tabular}{|c|c|c|c|c|c|c|c|c|}
\hline Parameter & Caphosol & $N$ & $\begin{array}{l}\text { Mean } \\
\text { reaction } \\
\text { value }\end{array}$ & $\begin{array}{l}\text { Standard } \\
\text { deviation }\end{array}$ & $\begin{array}{c}\text { Mean } \\
\text { difference }\end{array}$ & $\begin{array}{c}\text { Left } \\
\text { borderline } \\
95 \% \mathrm{Cl}\end{array}$ & $\begin{array}{c}\text { Right } \\
\text { borderline } \\
95 \% \mathrm{Cl}\end{array}$ & $\begin{array}{c}P \\
T \text {-Test }\end{array}$ \\
\hline CTV mucositis & $\begin{array}{l}0 \\
1\end{array}$ & $\begin{array}{l}50 \\
50\end{array}$ & $\begin{array}{l}1.2906 \\
0.7993\end{array}$ & $\begin{array}{l}0.41222 \\
0.35302\end{array}$ & 0.49137 & 0.33279 & 0.64994 & $<0.001$ \\
\hline Boost mucositis & $\begin{array}{l}0 \\
1\end{array}$ & $\begin{array}{l}50 \\
50\end{array}$ & $\begin{array}{l}1.7681 \\
1.2215\end{array}$ & $\begin{array}{l}0.53435 \\
0.45388\end{array}$ & 0.54657 & 0.34170 & 0.75145 & $<0.001$ \\
\hline Dysphagia & $\begin{array}{l}0 \\
1\end{array}$ & $\begin{array}{l}50 \\
50\end{array}$ & $\begin{array}{l}1.4590 \\
0.8230\end{array}$ & $\begin{array}{l}0.57327 \\
0.50210\end{array}$ & 0.63606 & 0.41348 & 0.85865 & $<0.001$ \\
\hline Xerostomia & $\begin{array}{l}0 \\
1\end{array}$ & $\begin{array}{l}50 \\
50\end{array}$ & $\begin{array}{c}1.1142 \\
0.8493\end{array}$ & $\begin{array}{l}0.31264 \\
0.36668\end{array}$ & 0.26498 & 0.12490 & 0.40505 & $<0.001$ \\
\hline
\end{tabular}




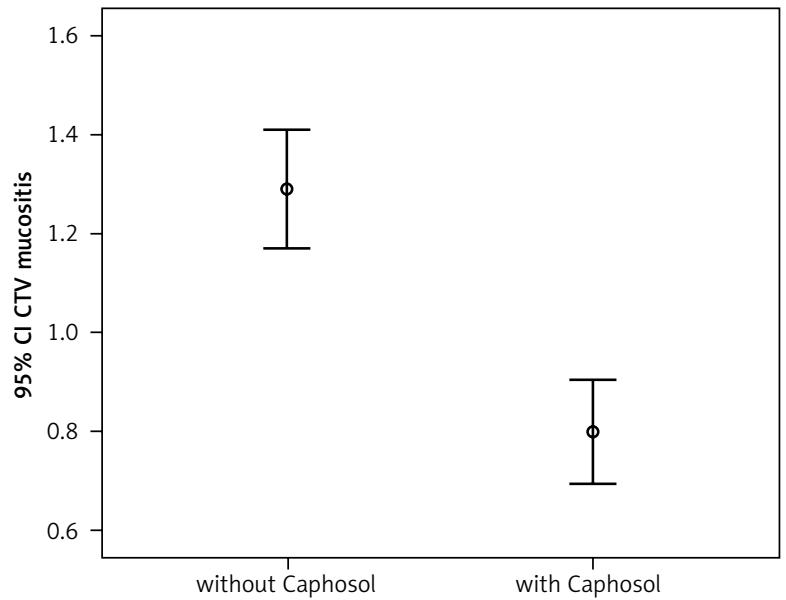

Fig. 1. Comparison of the severity of early mucositis reaction in the CTV area in the analysed groups

t-test or the nonparametric Mann-Whitney test was used to test the significance of differences for continuous variables, depending on their distribution. Percentage values were compared using the $\chi^{2}$ independence test. All comparisons were made at the statistical significance level $\alpha$ $=0.05$. The estimated values were presented with the $95 \%$ confidence interval (Cl).

\section{Results}

A statistically significant difference in mean severity of acute side effects between two matched groups was observed in: mucositis level in the CTV area, mucositis level in the escalated dose (boost) area, dysphagia and xerostomia ( $p<0.001$ for all reactions). In the group of patients receiving Caphosol the mucositis was less intense, both in the CTV and in the boost area. The fact of reduced severity of dysphagia in patients receiving Caphosol is an interesting observation. The difference is much greater than the effect of the reduction of mucositis level in the

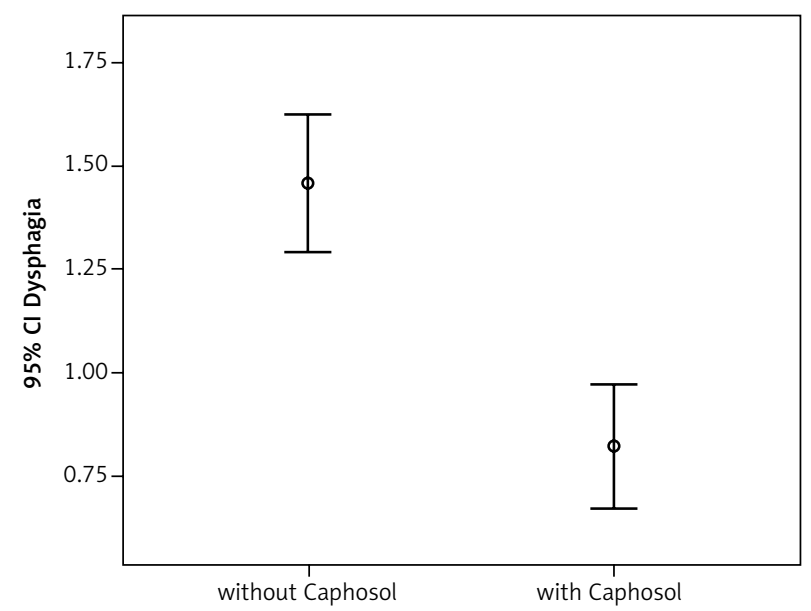

Fig. 3. Comparison of the severity of dysphagia in the analysed groups

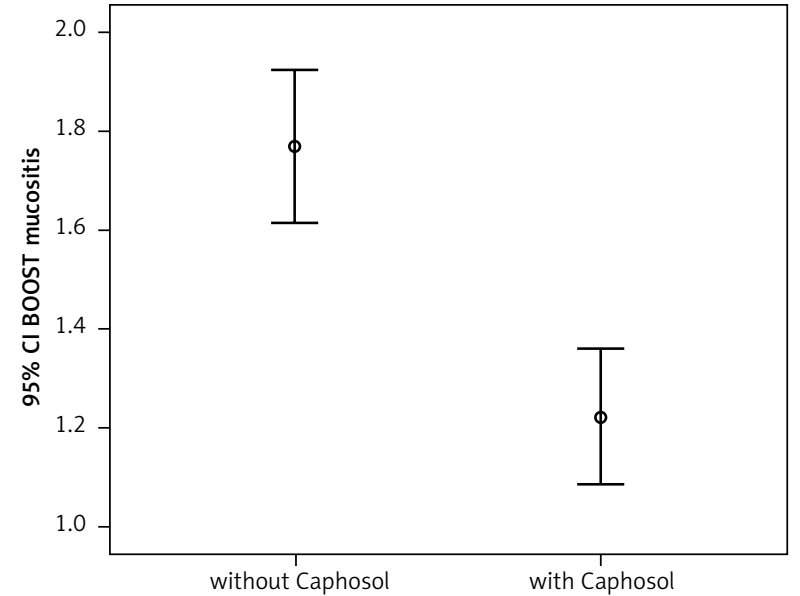

Fig. 2. Comparison of the severity of early mucositis reaction in the boost area in the analysed groups

boost area. Thus, it can be concluded that despite severe mucositis the patients who used Caphosol were able to swallow. The mean values for the reactions and the mean differences with $95 \% \mathrm{Cl}$ are presented in Table 3 and illustrated in Figs. 1-4. Lower use of opioid analgesia in radiotherapy patients receiving Caphosol compared to those receiving standard treatment for oral mucositis was noted $(p<0.001)$ (Fig. 5). There was also a difference in the frequency of prolonged hospitalizations between these two groups of patients. In the experimental group patients did not have reduced prolonged hospitalization due to severe post-treatment mucositis ( $p<0.001)$ (Fig. 6). There were no statistically significant differences in the use of dietary supplements, NSAIDs and mucolytic agents between the two groups. The results of subjective patient satisfaction with reduction of dryness and improvement of comfort in the oral cavity after Caphosol are presented in Fig. 7. The median for both assessments was higher than 50\% (slight improvement) with statistical significance $(p<0.001)$ and

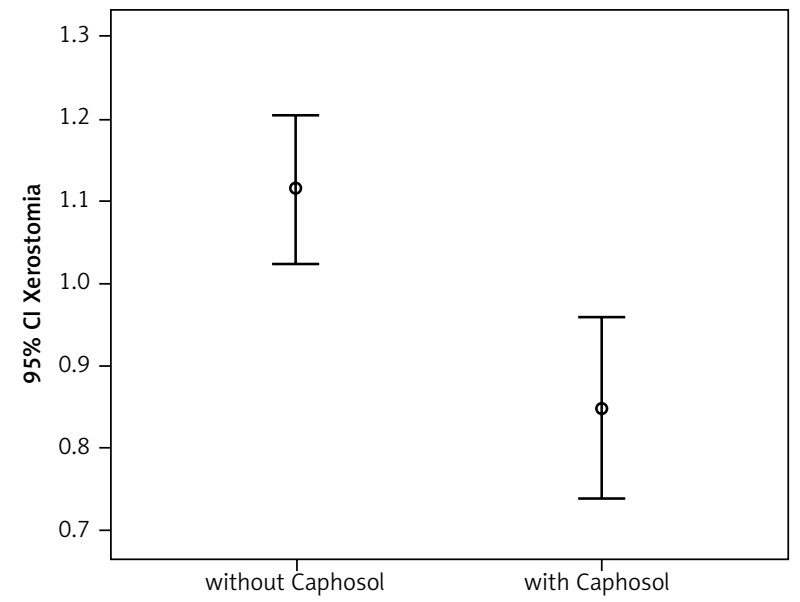

Fig. 4. Comparison of the severity of xerostomia in the analysed groups 


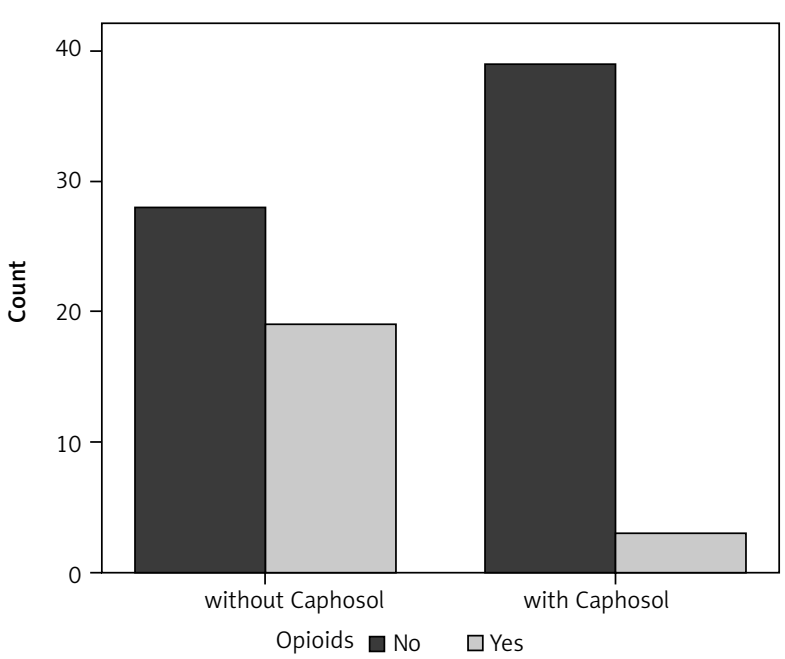

Fig. 5. Comparison of the opiods use in the analysed groups

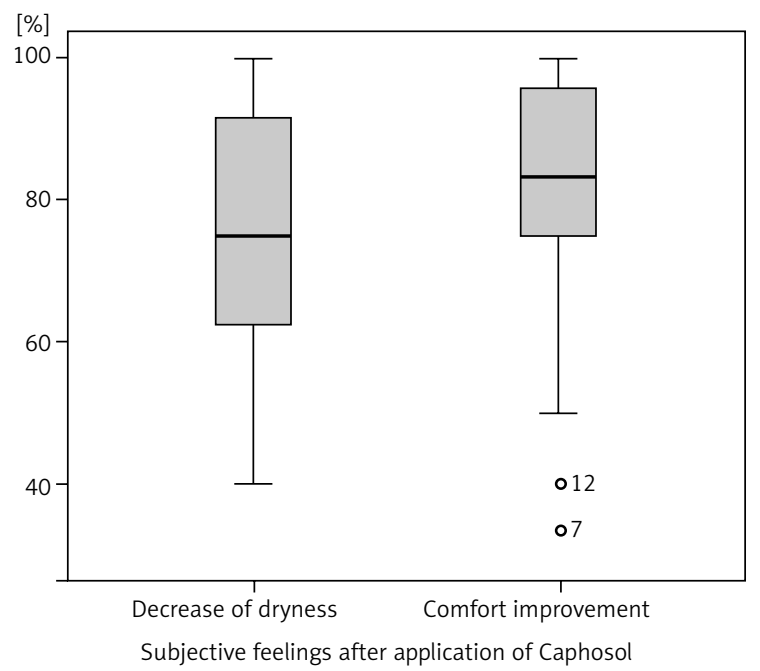

Fig. 7. Assessment of xerostomia and increase of oral cavity comfort improvement in the analysed groups

was, together with $25 \%$ and $75 \%$ quartiles for dryness reduction and comfort improvement, 75\% (58\%, 92\%) and $83 \%(75 \%, 100 \%)$, respectively, whereas the respective minimum and maximum borderline values were $40 \%$ and $100 \%$, and $33 \%$ and $100 \%$.

\section{Discussion}

All patients treated with radiation therapy alone or in combination with chemotherapy for the head and neck region develop mucositis in the oral cavity, which has a negative influence on overall treatment time and quality of life. The patients often require administration of narcotic analgesics, parenteral nutrition, and antibiotics. Severe mucositis may lead to prolonged or additional hospital stay and therapy interruptions [14].

There are several products available for the treatment of oral mucositis. Some of them prevent oral mucositis by their anti-inflammatory potential and protect the oral mucosa. Others help maintain oral hygiene, and moisten and lubricate the oral cavity. The efficacy of all of these

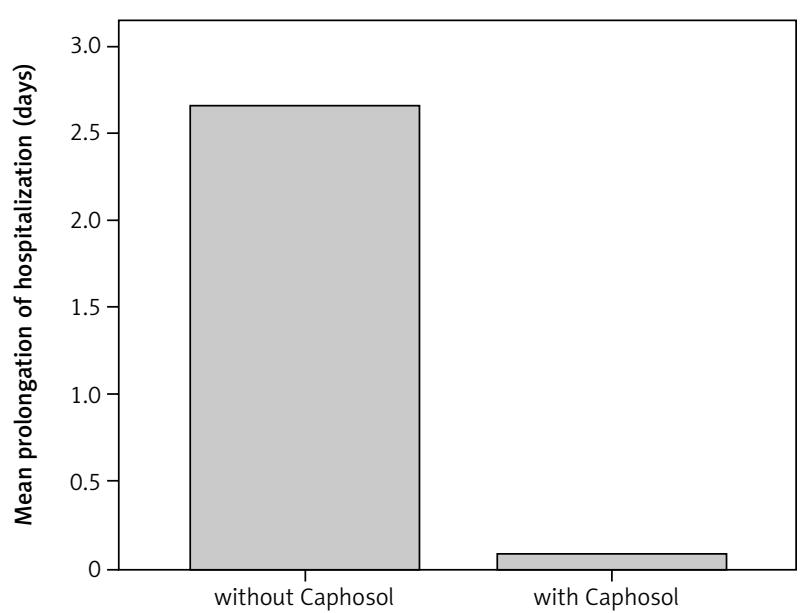

Fig. 6. Mean prolongation of hospitalization time (days) in the analysed groups

products is not well established, and there is still no "gold standard" for oral mucositis prevention and treatment. Apart from the clinical efficacy, it is important to consider the potential reduction in healthcare costs (length of hospitalization, analgesia, and specialist care) that could be achieved by preventing or reducing the incidence and/or duration of severe oral mucositis, when cost-effectiveness has become a necessary aspect of health commissioning. Many publications and numerous single-centre observations of Caphosol efficacy have been published during the past few years. Recent British guidelines on prevention and treatment of oral mucositis prepared by a UK multidisciplinary expert group of cancer and palliative care specialists suggest the use of a Caphosol rinse 4-10 times a day from the first day of treatment [15]. Most studies concerning the use of Caphosol in prevention and treatment of oral mucositis had a single-center design and compared patients receiving Caphosol with a matched group or historic controls receiving standard therapy [16-18]. The majority of these studies reported a lower incidence and severity of oral mucositis in patients receiving high-dose chemotherapy due to hematology malignancies and radiotherapy [19]. Only a few studies investigating the efficacy of Caphosol in patients treated with radio- or radiochemotherapy for head and neck cancer have been published to date. In two studies no preventive effect of Caphosol in severity of mucositis in this group of patients was found [20, 21 ], but despite this observation $50 \%$ of patients reported reduction of oral mucositis related symptoms, which was correlated with pain, swallowing and eating. In the present study reduction of severity of irradiation-induced mucositis was observed in the experimental group of patients in the CTV (clinical target volume) area and in the boost volume (the volume receiving a higher dose per fraction) area in comparison to the control group, and the difference was significant $(p<0.001)$. In the boost volume the severity of mucositis was increased, but it was lower as compared to the control matched group. The fact of reducing severity of dysphagia in patients receiving Caphosol is a very interesting observation. The difference is higher than the effect of 
Caphosol in reduction of mucositis in the boost area. Thus, it can be concluded that despite severe mucositis the patients receiving Caphosol were able to swallow and could eat. This observation is very similar to the data mentioned above. The reduction of opioid use observed in the present study agrees well with data from other publications. Data from the few studies suggest that Caphosol is well tolerated. Patients using Caphosol from the first day of treatment reported higher satisfaction, lower incidence of subjective feeling of dry mouth, and improvement of comfort in the oral cavity. These data are very similar to observations from many different studies. The effect of Caphosol on duration of hospitalization also seems to be important [22]. It was found that none of the Caphosol-treated patients had oral mucositis-related hospitalization, compared with $19 \%$ in the control group. In the present study shorter time of hospitalization due to post-treatment mucositis was observed. This observation correlates with data published by Godfrey and Cuccurullo from 2010 [23]. The effect of Caphosol on duration of hospitalization and opioid use may reduce the overall costs of treatment. The positive effect of Caphosol on comfort in the oral cavity and reduction of mucous dryness, evident on the basis of the patients' assessments, is also very important. Improved comfort in the oral cavity and reduced dryness of the oral mucous may have a positive influence on the patient's quality of life.

Despite the small size of the analyzed patient population, the differences are statistically significant. Hence we can conclude that Caphosol plays an important role in prevention and alleviation of irradiation-induced mucositis.

The authors declare no conflict of interest.

\section{References}

1. Trotti A, Bellm LA, Epstein JB, et al. Mucositis incidence, severity and associated outcomes in patients with head and neck cancer receiving radiotherapy with or without chemotherapy: a systematic literature review. Radiother Oncol 2003; 66: 253-62.

2. Sonis ST. Perspectives on cancer therapy induced - induced mucosal injury: pathogenesis, measurements, epidemiology. Cancer; 2004, 100: 1995-2025.

3. Scardina GA, Pisano T, Messina P. Oral mucositis. Review of literature. N Y State Dent J 2010; 76: 34-8.

4. Rodriguez-Caballero AD. Torres-Lagares Cancer treatment-induced oral mucositis: a critical review. Int J Oral Maxillofac Surg 2012; 41: 225-38.

5. Lalla RV, Peterson DE Treatment of mucositis, including new medications. Cancer J 2006; 12: 348-54.

6. Nicolatou-Galitis O, Velegraki A, Sotiropoulou-Lontou A, et al. Effect of fluconazole antifungal prophylaxis on oral mucositis in head and neck cancer patients receiving radiotherapy. Support Care Cancer 2006; 44 51.

7. Kazemian A, Kamian S, Aghili M, Hashemi FA, Haddad P. Benzydamine for prophylaxis of radiation-induced oral mucositis in head and neck cancers: a double-blind placebo-controlled randomized clinical trial. Eur J Cancer Care 2009; 18: 174-80.

8. Veness MJ, Foroudi F, Gebski V, Timms I, Sathiyaseelan Y, Cakir B, Tiver $\mathrm{KW}$. Use of topical misoprostol to reduce radiationinduced mucositis: results of a randomized, double-blind, placebo-controlled trial. Australas Radiol 2006; 50: 468-70.

9. Peterson DE, Jones JB, Petit 2nd RG. Randomized, placebo-controlled trial of Saforis for prevention and treatment of oral mucositis in breast cancer patients receiving anthracycline-based chemotherapy. Cancer 2007; 109: 322-30.

10. Raber-Durlacher JE, von Bultzingslowen J, Logan RM, et al. Study Group of MASCC/ISOO.Systemic review of cytokines and growth factors for management of oral mucositis in cancer patients. Support Cancer Care 2013; 21: 343-55.

11. Peterson D, Ohrn K, Bowen J, et al. Systemic review of oral cryotherapy for managment of oral mucositis caused by cancer therapy. Support Care Cancer 2013; 21: 327-32.

12. Migliorati C, Hewson I, Lalla RV, et al. Systemic review of laser and other light therapy for the management of oral mucositis in cancer patients. Support Care Cancer 2013; 21: 333-41.

13. Nicolatou-Galitis O, Sarri T, Bowen J, et al. Group of MASCC/ISOO. Systemic review of amifostine for management of oral mucositis in cancer patients. Support Care Cancer 2013; 21: 357-64.

14. Rodriguez-Caballero A, Torres-Lagares D. Cancer treatment-induced oral mucositis: a critical review. Int J Oral Maxillofac Surg 2012; 41: 22538

15. Quinn B. Efficacy of a supersaturated calcium phosphate oral rinse for the prevention and treatment of oral mucositis in patients receiving high-dose cancer therapy: a review of current data. Eur J Cancer Care (Engl) 2013; 22: 564-79.

16. Ambard N, Brechard C, Noyel J, et al. Prospective evaluation of supersaturated calcium phosphate oral rinse for oral mucositis after autologous and allogeneic stem cell transplantation. $37^{\text {th }}$ Annual Meeting of the European Group for Blood and Marrow Transplantation. 2011.

17. Dłuzniewska A, Gozdzik J, Zygadlo D, Skoczen S, Krasowska-Kwiecień A, Czogala W, Wiecha O. Supersaturated calcium phosphate rinse (Caphosol) in the management of mucositis after haematopoietic stem cell transplantation - single-centre experience. $37^{\text {th }}$ Annual Meeting of the European Group for Blood and Marrow Transplantation. 2011.

18. Rzepecki P, Wasko-Grabowska A, Oborska S, Młot B. Use of a calcium phosphate mouth rinse for prevention of oral mucositis after haematopoietic stem cell transplantation: single-centre experience. $36^{\text {th }}$ Annual Meeting of the European Group for Blood and Marrow Transplantation. 2010.

19. Haas M, Mercedes T, Manyak M. Treatment of Oral Mucositis by Supersaturated Calcium Phosphate Oral Rinse in Patients Receiving Chemo-therapy (CT) and Radiation (RT). American Society for Radiation Oncology $50^{\text {th }}$ Conference. Conference Proceedings 2008. Abstract 2530.

20. Rao N, Trotti A, Kim J, et al. Phase II multicenter trial of Caphosol for the reduction of mucositis in patients receiving radiation therapy for head and neck cancer. Int J Radiat Oncol Biol Phys 2011; 81 (Suppl. 2): S75.

21. Stokman M, Burlage F, Spijkervet F. The effect of a calcium phosphate mouth rinse on chemo/radiation induced oral mucositis in head and neck cancer patients. A prospective study. Support Care Cancer 2010; 18 Suppl S114; Abstract 08-075.

22. Miyamoto C, Wobb J, Micaily B, Li S, Achary M. A retrospective match controlled study of supersaturated calcium phosphate oral rinse (SCPOR) vs. supportive care for radiation induced oral mucositis. International MASCC/ISOO symposium. 2009.

23. Godfrey L Cuccurullo C. Analysis of mucositis-associated health outcomes in patients treated with image-guided IMRT for head and neck cancer: should Caphosol be included in the MASCC/ ISOO mucositis guidelines? Support Care Cancer 2010; 18 Suppl S108-S109; Abstract 08-064.

\section{Address for correspondence}

\section{Dorota Kiprian}

Comprehencive Cancer Center

Warsaw, Poland

Roentgena 5

02-781 Warsaw, Poland

e-mail:dkiprian@wp.pl

Submitted: 15.04 .2014

Accepted: 14.01 .2016 